\title{
Magnitude of malnutrition and associated factors among HIV infected children attending HIV-care in three public hospitals in East and West Gojjam Zones, Amhara, Northwest, Ethiopia, 2017: a cross-sectional study
}

\author{
Yihenew Sewale ${ }^{1}$, Getachew Hailu ${ }^{3}$, Mizinew Sintayehu ${ }^{2}$, Nurilign Abebe Moges ${ }^{3 *}$ and Animut Alebel ${ }^{2}$
}

\begin{abstract}
Objective: The main aim of this study was to assess the magnitude of malnutrition and associated factors among HIV infected children in Amhara Regional State, and Northwest Ethiopia. This study is a result of single observation.

Results: A total of 372 study participant were interviewed, of which $60.2 \%, 95 \% \mathrm{Cl}(55.90-65.60)$ were malnourished. Children who had good individual dietary diversity were $53 \%$ times less likely malnourished as compared to children who had fair/poor dietary diversity $(A O R=0.474,95 \% \mathrm{Cl}(0.26,0.86))$. Sex of child, Age of the child, undiversified diet, comorbidity disease, oral ulcer, diarrhea and history of hospital admission were found statically significant associated with malnutrition. Magnitudes of malnutrition among HIV infected children were very high. The early detection and control progression of HIV, closely follow up to intervene this situation is highly recommended.
\end{abstract}

Keywords: Malnutrition, Magnitude, Associated factors, Ethiopia

\section{Introduction}

Worldwide malnutrition is the major underlying cause of death in children [1]. Each year it claims the lives of over one million children were dead and develop severe acute malnutrition. Among children with severe malnutrition, mortality risk is three times higher in HIV-infected children than in non-HIV-infected children [2, 3].

The harmful effect of malnutrition is more common in HIV infected children, For example, wasting and weight loss are common features of HIV infected children $[4,5]$. Use of ART without nutritional support, or nutritional support without ARTs, will often result in poor treatment responses and outcomes [6].

So WHO recommended that asymptomatic HIV infected children should increase his/her energy intake

\footnotetext{
*Correspondence: nure113@gmail.com

${ }^{3}$ Public Health Department, Medicine and Health Sciences College, Debre Markos University, Debre Markos, Ethiopia

Full list of author information is available at the end of the article
}

by $10 \%$, compared to a non-infected child but if they were symptomatic HIV infection or episodes of opportunistic infection developed also added to up to $20-30 \%$ and when a severe malnutrition episode occurs added up to $50-100 \%$ [7]. The study which is conducted in Bangladesh the magnitude of malnutrition in HIV infected children differs from males to females. These showed that $33.2 \%$ males and $26.7 \%$ of females were malnourish and it was similar in Addis Ababa, Ethiopia [8, 9].

However, despite the seriousness of the problem, the number of studies conducted to explain factors that contribute to malnutrition among HIV infected children is still relatively inadequate particularly programmatic implications are not paid attention. This is the main reason for undertaking this research hoping that it will shed some light on the issue and provide important information both to the clinicians and to the programmers to manage malnutrition among HIV infected children. 


\section{Main text Methods}

The study used institutional based comparative crosssectional study was conducted in three public hospitals. It was conducted at Finote Selam primary hospital, Shegaw Motta primary hospital and Debre Markos Referral Hospital in Amhara Regional State from February 20, 2017 to April 20, 2017. These three selected sites were serving more than 1 million, 990,000 and 3.5 million people respectively. In Debre Markos referral hospital, 326 were HIV infected children of which 168 male and 158 female. In Finote Selam primary hospital, 127 were HIV infected children of which 63 males and 64 females and from 990,000 people 128 were HIV infected of which 58 males and 70 females HIV/AIDS infected children had followed up care respectively [10-12]. The sampled patients (age 2-14 years) who tested positive for HIV/ AIDS and were being routinely followed for HIV care or sooner as the clinical providers. The sample size was determined using a difference between two population proportions, considering the following conditions [13]:

1. The proportion of HIV infected wasted children of male $12.9 \%$ and of female $34.9 \%$.

2. The proportion of HIV infected underweight children of male $24.7 \%$ and of female $16.4 \%$.

3. The proportion of HIV infected stunted children of male $34.3 \%$ and of female $26.2 \%$.

4. With $5 \%$ level of significance $(\alpha)$, at $95 \%$ level of confidence for two tail test, $r$ is the ratio of the size of sample 2 to sample $1=1$ and a Power of $(1-B))=80 \%$. The required sample size is calculated as follows:

$$
\text { let } \begin{aligned}
r & =\frac{n_{2}}{n_{1}} \text { and } \mathrm{P}=\frac{\mathrm{n}_{1} p_{1}+\mathrm{n}_{2} p_{2}}{\mathrm{n}_{1}+n_{2}} \\
& =\frac{p_{1}+\mathrm{r} p_{2}}{1+r} \text { is the common population proportion }
\end{aligned}
$$

an interview, anthropometric measurement and clinical records review from the register of each hospital. Sampling interval (Kth) was determined by dividing the total HIV/AIDS positive males and females' children in each hospital allocated sample size of each hospital males and females' children. For DMRH k1 $=168 / 108=2$ and $\mathrm{K} 2=158 / 100=2, \quad \mathrm{SMPH} \quad \mathrm{k} 1=58 / 38=2$ and $\mathrm{K} 2=70 / 45=2$, FSPH k1 $=63 / 40=2$ and $64 / 41=2$ where $\mathrm{k} 1=$ male and $\mathrm{K} 2=$ female. The first sample was selected by simple random sampling from clinical records and every (kth) record was selected for gathering information until the required sample was obtained from each Hospital.

Data collectors were recruited and conducted 2-day training by principal researcher. Anthropometric measurements, record review, and face to face interview were conducted. Weight and height/were measured for each subject. During data collection, nutritional advice was provided to all caregivers and who had a malnourished child were linked to the therapeutic feeding program. The pre-test was conducted at Debre Markos health center. During data collection, all the activities were carefully monitored and supervised. Weights and height/were measured using standardized tools and calibration was applied daily. The questionnaire was prepared in English and translated to Amharic.

Operational definitions used in this study are malnutrition: is defined WAZ or WHZ or HAZ or BAZ below $-2 \mathrm{SD}$ of the median or WAZ or WHZ or HAZ or BAZ above 2 SD value of WHO standard respectively.

Data processing and analysis; data were entered into EPI DATA version 3.1 and analysis were done using SPSS version 20 statistical package and WHO child growth standards 2007 software. The anthropometric measurement was converted physical growth indicators (WHZ, WAZ, HAZ and BAZ) and was used WHO anthro and WHO anthroplus software. Logistic regressions analysis

$$
\mathrm{n}_{1}=\frac{\left[Z \alpha_{/ 2} \sqrt{\left(1+\frac{1}{r}\right) p(1-p)}+Z_{\beta} \sqrt{p_{1}\left(1-p_{1}\right)+\left(\frac{p_{2}\left(1-p_{2}\right)}{r}\right)}\right]^{2}}{\left(p_{1}-p_{2}\right)^{2}}
$$

Taking the largest sample size 1028 obtained for wasting from the above calculation and correcting for a finite population of size 581 target populations, the required sample size is 372 (186 male and 186 female).

The sampling procedure was a total of 581 HIV/AIDS positives children who had to follow up of the ART care in the study facilities, 372 participants were proportionately selected each study site. A systematic sampling technique was used to select the participants for was computed to assess the associations of the various factors against the level of malnutrition. Variables with a p-value of less than 0.2 in the bivariate analysis were entered into the final model. A p-value $<0.05$ at $95 \% \mathrm{CI}$ was considered statistically significant. The strength of association between associated factors and outcome variables were assessed using odds ratio. Since all study participants were children, their parents or guardians gave informed consent. 


\section{Results}

Socio-economic characteristics given below as a total of $372 \mathrm{HIV} / \mathrm{AIDS}$ infected children were a participant in the study with the response rate of $100 \%$. The magnitude of malnutrition among HIV/AIDS infected Children were; totally 224 (60.2\%) HIV/AIDS infected children were malnourished among the studied children.

Among the children studied, 186 (50\%) and 186 (50\%) were males and females respectively. among the children studied, 126 (67.7\%) and 98 (52.7\%) were malnourished males and females respectively, 52 (96.3\%) were found in age group of 2-5 year, 72 (48.3\%) were found in age group of 5-10 year and 100 (59.2\%) were found in age group of $10-15$ years. The mean $( \pm S D)$ age of children included in the study was $9.6( \pm 3.2)$ years ranging from 2 to 14 years (Table 1 ).

Dietary characteristics of study participant, 176 (47.7\%) reported good food variety and 196 (52.3\%) ate also fair/ poor food variety per $24 \mathrm{~h}$.

Clinical characteristics of HIV infected children. A total of $372(100 \%)$ the studied children, 343 (92.2\%) were received ART for greater than 12 months. Among the children studied 195 (52.4\%) and 106 (68\%) of which had WHO stage of (I and II) during the survey time respectively and $253(28.5 \%)$ and 87 (23.4\%) also had WHO stage of (I and II) the past 6 months respectively, whereas $15.4 \%$ and $20.8 \%$ of were had CD4 count less than 500 cell $/ \mathrm{mm}^{3}$ and $84.6 \%$ and $79.2 \%$ were above $500 \mathrm{cell} / \mathrm{mm}^{3}$ during the surveys time respectively. More than $1 / 3 \mathrm{rd}$ (177) of the study participant was developed an oral ulcer in the last 6 months and among them 109 (61.6\%) were malnourished.

Associated factors of malnutrition among HIV infected children; Children who were male 2.3 times more likely developed malnutrition as compared to female $\mathrm{AOR}=2.37(1.34,4.20)$. Age of child who was between 5 and 10 years were $96 \%$ times less likely developed malnutrition as compared to age between 2 and 5 years. Whereas age of a child between 10 and 15 year was $95.5 \%$ time less likely developed malnutrition as compared to age of between 2 and 5 years. Children who had good individual dietary diversity were $53 \%$ times less likely

Table 1 socioeconomic characteristics of HIV infected children who had to follow up in three public hospitals, Northwest, Ethiopia, 2017

\begin{tabular}{|c|c|c|c|}
\hline Variables & Categories & Frequency & Percent \\
\hline \multirow[t]{2}{*}{ Sex } & Male & 186 & 50 \\
\hline & Female & 186 & 50 \\
\hline \multirow[t]{3}{*}{ Age of child (years) } & $2-5$ & 54 & 14.5 \\
\hline & $5-10$ & 149 & 40.1 \\
\hline & $10-15$ & 169 & 45.4 \\
\hline \multirow[t]{2}{*}{ A child with alive mother } & Yes & 297 & 79.8 \\
\hline & No & 75 & 20.2 \\
\hline \multirow[t]{4}{*}{ Age of mother } & $15-24$ & 8 & 2.2 \\
\hline & $25-34$ & 122 & 32.8 \\
\hline & $35-49$ & 159 & 42.5 \\
\hline & $\geq 50$ & 9 & 2.4 \\
\hline \multirow[t]{2}{*}{ Residence } & Rural & 82 & 22 \\
\hline & Urban & 290 & 78 \\
\hline \multirow[t]{6}{*}{ Occupation of mother $(n=297)$} & Student & 2 & 0.5 \\
\hline & Daily laborer & 102 & 27.4 \\
\hline & Employed & 53 & 14.2 \\
\hline & Farmer & 51 & 13.7 \\
\hline & Merchant & 62 & 16.7 \\
\hline & Other & 27 & 7.7 \\
\hline \multirow[t]{2}{*}{ School attended $(N=297)$} & Yes & 142 & 47.8 \\
\hline & No & 155 & 52.2 \\
\hline \multirow[t]{5}{*}{ Level of maternal education } & Unable to read and write & 99 & 26.6 \\
\hline & Able to read and write & 53 & 14.2 \\
\hline & Primary school & 58 & 15.6 \\
\hline & Secondary school & 44 & 11.8 \\
\hline & College/university & 43 & 11.6 \\
\hline
\end{tabular}


develop malnutrition as compared to children who had fair/poor dietary diversity ( $\mathrm{AOR}=0.47,95 \% \mathrm{CI}(0.26$, $0.86)$ ). In addition, children who had diarrhea that stays for 2 weeks in the last 6 months were 3.3 times more likely to be malnourished as compared who had no diarrhea $(\mathrm{AOR}=3.30 \mathrm{CI}(1.41,7.72))$. Children who had an ulcer oral also were 2.3 times more likely develop malnutrition as compared to children who had no oral ulcer $(\mathrm{AOR}=2.30,95 \% \mathrm{CI}(1.41,7.60))$. Children who had no comorbidity disease were 65.2 times less likely developed malnutrition, as compared to these, had comorbidity disease $(\mathrm{AOR}=0.34,95 \% \mathrm{CI}(0.15,0.800))$. Children who had no history of hospital admission were also $66.4 \%$ times less likely malnutrition as compared to who had a history of hospital admission $(\mathrm{AOR}=0.34,95 \% \mathrm{CI}(0.13$, 0.84)) (Table 2).

\section{Discussion}

This study investigated the magnitude and associated factors of all types of malnutrition and associated factors among HIV infected children in Northwest Ethiopia.

About three out of five HIV positive children were malnourished. The finding implied that HIV infected children in the current study area were in the worst condition compared to malnutrition reported in Nigeria [14]. This could probably attribute the difference in the characteristics of study participants. On the other hand, the current prevalence was similar in a study Bobo Dioulasso City, Burkina Faso and Cameroon [23, 24]. Thus, malnutrition is still a major public health problem in Africa in general and in Ethiopia in particular.

Boys were more liekly to be malnourished compared to girls. Such finding was similar with study in Tanzania among children born to HIV-infected mothers; boys were more likely affected. About $28 \%$ were stunted, $40 \%$ were wasted and $28 \%$ were underweight compared to girls [8]. This can be explained that boys need more close investigation of malnutrition and appropriate management is needed. The reason might be due to sex preference and unbalanced care of children based on their sex [15]. Yet, the reasons for this association between gender and malnutrition have to be explored using qualitative study in order to explore feeding practice based on gender difference [9]. Those children older than 5 years and beyond were less likely to be malnourished compared those below 2 years. The reason can be the older children adapted feeding situation and opportunistic infections are managed. However, it was contracting with other studies that found older children were more likely to experience malnutrition [16, 17]. The discrepancy can be explained as young children metabolic needs for growth and development is higher than older once. This hypothesizes that the younger children are prone to fast in the HIV-disease progression but with higher needs of caloric intake $[1,18]$. Hence, children less than 2 years need special attention in order to ensure adequate energy requirement was met.

Table 2 Multivariate analysis of selected variables associated factor for malnutrition in HIV/AIDS infected children on HIV-care who had followed up in three public Hospitals, northwest, Ethiopia

\begin{tabular}{|c|c|c|c|c|c|}
\hline \multirow[t]{2}{*}{ Variables } & \multirow[t]{2}{*}{ Categories } & \multicolumn{2}{|c|}{ Malnutrition } & \multirow[t]{2}{*}{ COR $95 \% \mathrm{Cl}$} & \multirow[t]{2}{*}{ AOR $95 \% \mathrm{Cl}$} \\
\hline & & Yes & No & & \\
\hline \multirow[t]{2}{*}{ Sex of the child } & Male & $126(60.2)$ & $60(32.3)$ & $1.89(1.24,2.87)$ & $2.37(1.34,4.20)$ \\
\hline & Female & $98(52.7 \%)$ & $88(47.3)$ & 1 & 1 \\
\hline \multirow[t]{3}{*}{ Age of child (years) } & $2-5$ & $52(96.3 \%)$ & $2(3.7 \%)$ & 1 & 1 \\
\hline & $5-10$ & $72(48.3 \%)$ & 77 (51.7\%) & $0.04(0.01,0.15)$ & $0.04(0.01,0.21)$ \\
\hline & $10-15$ & $100(59.2 \%)$ & $69(40.8 \%)$ & $0.06(0.01,024)$ & $0.05(0.01,0.25)$ \\
\hline \multirow[t]{2}{*}{ Dietary diversity } & Good & $110(62.5 \%)$ & $66(37.5 \%)$ & 1 & 1 \\
\hline & Fair/poor & $114(58.2 \%)$ & $82(41.8 \%)$ & $1.20(0.79,1.82)$ & $0.47(0.26,0.86)$ \\
\hline \multirow{2}{*}{$\begin{array}{l}\text { Presences of co morbidity } \\
\text { disease }\end{array}$} & Yes & $39(53.4 \%)$ & $34(46.6 \%)$ & $0.70(0.42,1.18)$ & $0.34(0.15,0.80)$ \\
\hline & No & 185 (61.9\%) & $114(38.1 \%)$ & 1 & 1 \\
\hline \multirow[t]{2}{*}{ Diarrhea } & Yes & $58(65.9 \%)$ & $30(34.1 \%)$ & $1.37(0.80,2.27)$ & $3.30(1.41,7.72)$ \\
\hline & No & $166(58.5 \%)$ & $118(45.5 \%)$ & 1 & 1 \\
\hline \multirow[t]{2}{*}{ Ulcer of oral } & Yes & 109 (61.6\%) & 68 (58.4\%) & $1.12(0.74,1.69)$ & $2.30(1.41,7.60)$ \\
\hline & No & 115 (59\%) & $80(41 \%)$ & 1 & 1 \\
\hline \multirow[t]{2}{*}{ Hospital admission } & Yes & $40(58 \%)$ & $29(42 \%)$ & $1.12(0.66,1.91)$ & $0.34(0.13,0.84)$ \\
\hline & No & $184(60.7 \%)$ & 119 (39.3\%) & 1 & 1 \\
\hline
\end{tabular}


In the current study children who had diarrhea were 3.3 times more likely developed malnutrition than who had not diarrhea. This is similar to other studies elsewhere $[19,20]$. This can be explained due to alteration of gastro intestine tract function or malabsorpation of food. Similarly, those who had oral ulcer had also statically significant associated with malnutrition. These findings were in line with the studies conducted in other areas revealed those with gastro intestine (GI) disorders were associated with malnutrition in HIV infected patients $[4,21-25]$. This could be due to difficulty of eating or chewing. In addition, the disease could be brought loss of appetite and decrease peristalsis of gastro intestine tract. This implied that opportunistic infections have to be managed and symptomatic treatment is necessary to restore food intake of children with GI symptoms.

The strength of this study is it balanced male and female children, it is conducted in low resource setting and it give information on the linkage of HIV and malnutrition among children. Further prospective study is recommended to observe nutritional status overtime. Qualitative study may also help to investigate the reason why male were more malnourished than females? Finally, policy makers can use the information to improve HIV and nutrition interventions based on the result.

\section{Limitations of the study}

Since the study used cross sectional study,

- It cannot establish the cause effect relationship between the dependent and the independent variable. Hence, prospective study design supplemented with qualitative approach will solve the limitations of this study.

\section{Abbreviations}

AIDS: acquired immune deficiency syndrome; ART: anti retro viral therapy: CD4: cluster differentiation of T-lymphocyte cells; HIV: human immune deficiency virus; IDD: individual dietary diversity; WHO: World Health Organization.

\section{Authors' contributions \\ YS contributed to the design of this study. YS and AA collected data, YS, NAM, GH and MS assist in analyzed and interpreted the data; AA, YS and NAM drafted the manuscript for important intellectual content. All the authors reviewed and revised the draft further and approved the final version for submission. All authors read and approved the final manuscript.}

\section{Author details}

${ }^{1}$ Nursing Department, Medicine and Health Sciences College, Debre Berhan University, Debre Berhan, Ethiopia. ${ }^{2}$ Nuring Department, Medicine and Health Sciences College, Debre Markos University, Debre Markos, Ethiopia. ${ }^{3}$ Public Health Department, Medicine and Health Sciences College, Debre Markos University, Debre Markos, Ethiopia.

\section{Acknowledgements}

The authors acknowledged to all selected study sites officials whom we have contacted and allowed us to conduct this project.

\section{Competing interests}

The authors declare that they have no competing interests.

\section{Availability of data and materials}

Data will be available upon request of the corresponding author.

\section{Consent for publication}

Not applicable.

\section{Ethical approval and consent to participant}

Ethics approval was obtained from Debre Markos University research ethics approval committee prior to data collection. Permission was obtained from the selected Hospitals administrators. Verbal consent was taken from each client parents or guardians after the purpose of the study was explained. They were told to withdraw at any time and/or to refrain from responding to questions they were not interested to respond. Client parents were also informed that all the data obtained from clients would be kept confidential using codes instead of any personal identifiers and if there is a problem, it was link to for malnutrition management.

Funding

Not applicable.

\section{Publisher's Note}

Springer Nature remains neutral with regard to jurisdictional claims in published maps and institutional affiliations.

Received: 31 August 2018 Accepted: 25 October 2018

Published online: 03 November 2018

References

1. Müller $\mathrm{O}$, Krawinkel M. Malnutrition and health in developing countries CMAJ. 2005;173(3):279-86.

2. Musoke PM, Fergusson P. Severe malnutrition and metabolic complications of HIV-infected children in the antiretroviral era: clinical care and management in resource-limited settings. Am J Clin Nutr. 2011:94(1):1716S-20S.

3. Chinkhumba J, Tomkins A, Banda T, Mkangama C, Fergusson P. The impact of HIV on mortality during in-patient rehabilitation of severely malnourished children in Malawi. Trans R Soc Trop Med Hyg. 2008; 102:639-44.

4. Duggal S, Chugh TD, Duggal AK. HIV and malnutrition: effects on immune system. Clin Dev Immunol. 2012;2012:1-8.

5. Mwiru RS, Spiegelman D, Duggan C, Seage GR, Semu H, Chalamilla G, et al. Nutritional status and other baseline predictors of mortality among HIV-infected children initiating antiretroviral therapy in Tanzania. J Int Assoc Provid AIDS Care. 2013. https://doi.org/10.1177/232595741350085 2.

6. Central Statistical Agency and ICF international. Ethiopia Demographic and Health Survey 2011. 2012. Central Statistical Agency and ICF international: Addis Ababa and Maryland.

7. Garcia-Prats AJ, McMeans AR, Ferry GD, Klish WJ. Nutrition and HIV/AIDS. HIV Curric. 2010:286:4-5.

8. Choudhury KK, Hanifi MA, Rasheed S, Bhuiya A. Gender inequality and severe malnutrition among children in a remote rural area of Bangladesh. J Health Popul Nutr. 2000;18(3):123-30.

9. The United States president's emergency plan for AIDS relief, Report on Food and Nutrition for People with HIV/AIDS May. 2006.

10. Finot Selam Primary Hospital annual report. 2016.

11. Shegaw Motta District Annual report. 2016.

12. Debre Markos Referral Hospital annual report. 2016.

13. Wondimu WB. Nutritional status and associated factors in human immunodeficiency virus infected children in Hawassa University Referral Hospital Hawassa City, SNNPR, Ethiopia, EPHI. 2014.

14. Uwem FE, Akin MO, Morenike AD. Prevalence of malnutrition among settled pastoral Fulani children in Southwest Nigeria. BMC Res Notes. 2008;2:9. 
15. Henry W, Anne NA, Stefan P, James KT, Thorkild T. Boys are more stunted than girls in Sub-Saharan Africa: meta-analysis of 16 demographic and health surveys. BMC Pediatr. 2007;7:17.

16. Raphael OB, Funke IO, Segun BF, Foluke ES. Prevalence and determinants of malnutrition among under-five children of farming households in Kwara State, Nigeria: Canadian Center of Science and Education. J Agric Sci. 2011;3(3):173.

17. Bobby J, Aaron R, Poonam K, Vimal DR. Prevalence of malnutrition in Rural Karnataka, South India: a comparison of anthropometric indicators. J Health Popul Nutr. 2002;20(3):239-44.

18. Sharma TS, Kinnamon DD, Duggan C, Weinberg GA, Furuta L, Bechard $L$, et al. Changes in macronutrient intake among HIV-infected children between 1995 and 2004. Am J Clin Nutr. 2008;88(2):384-91.

19. Johann-Liang R, O’Neill L, Cervia J, Haller I, Giunta Y, Licholai T, et al. Energy balance, viral burden, insulin-like growth factor interleukin-6 and growth impairment in children infected with human immunodeficiency virus. AIDS. 2000;14(6):683-90

20. Trehan I, O'Hare BA, Phiri A, Heikens GT. Challenges in the management of HIV-infected malnourished children in Sub-Saharan Africa. AIDS Res Treat. 2012. https://doi.org/10.1155/2012/790786.
21. Sunguya BF, Poudel KC, Otsuka K, Yasuoka J, Mlunde LB, Urassa DP, et al. Under nutrition among HIV-positive children in Dares Salaam, Tanzania: antiretroviral therapy alone is not enough. BMC Public Health. 2011;11:869.

22. Saloojee H, De Maayer T, Garenne ML, Kahn K. What's new? Investigating risk factors for severe childhood malnutrition in a high HIV prevalence South African setting. Scand J Public Health Suppl. 2007;69:96-106.

23. Poda GG, et al. Malnutrition is associated with HIV infection in children less than 5 years in Bobo-Dioulasso City, Burkina Faso. Medicine. 2017;96(21):e7019.

24. Penda $\mathrm{Cl}$, et al. Malnutrition among HIV infected children under 5 years of age at the Laquintinie hospital Douala, Cameroon. Pan Afr Med J. 2018:30:91.

25. Castetbon K, Anglaret X, Attia A, Toure S, Dakoury-Dogbo N, Messou E, et al. Effect of early chemoprophylaxis with co-trimoxazole on nutritional status evolution in HIV-1-infected adults in Abidjan, Cote d'Ivoire. AIDS. 2001;15(7):869-76.
Ready to submit your research? Choose BMC and benefit from:

- fast, convenient online submission

- thorough peer review by experienced researchers in your field

- rapid publication on acceptance

- support for research data, including large and complex data types

- gold Open Access which fosters wider collaboration and increased citations

- maximum visibility for your research: over 100M website views per year

At BMC, research is always in progress.

Learn more biomedcentral.com/submissions 